\title{
Biological and practical lessons associated with the use of sexed semen
}

\author{
Simon P. de Graaf ${ }^{1}$, Tamara Leahy ${ }^{1}$ and Ramakrishnan Vishwanath ${ }^{2}$ \\ ${ }^{1}$ Faculty of Veterinary Science, The University of Sydney NSW 2006 Australia; ${ }^{2}$ Sexing Technologies, \\ 22575 State Hwy 6 Sth, Navasota, Texas, USA
}

\begin{abstract}
Summary
Numerous biological and practical lessons associated with the use of sexed semen have been learnt in the 15 years since it was released onto the commercial market. Over this time, concerns regarding the safety of sex-sorted spermatozoa have been largely allayed through the birth of several million pre-sexed calves, but the major issue that remains is that of reduced fertility. Numerous studies have demonstrated that the process of flow cytometric sorting and subsequent cryopreservation causes reduced in vitro and in vivo fertility of sexed semen, which cannot be wholly compensated for by increasing the number of spermatozoa inseminated. As a result of this diminished fertilising capacity, the use of sex-sorted bull spermatozoa was traditionally only recommended for insemination of heifers, not lactating, superovulated and/or synchronised animals due to the low fertility obtained. However, recent changes to the processing methods used during and after flow-sorting are showing the fertility of 'sexed semen' is improving for the first time in over a decade of commercial activity. With continued research and development of methods to improve the conditions under which spermatozoa are sorted and frozen and concurrent advancements in sorter technology, it is anticipated that the fertility and application of sexed semen will continue to increase.
\end{abstract}

\section{Introduction}

It is now almost three decades since sex-preselection of offspring was proven possible with the birth of a litter of female rabbit kits (Johnson et al. 1989). This remarkable achievement was made possible by a modified flow cytometer able to separate spermatozoa into $X$ and $\mathrm{Y}$ chromosome bearing populations based on their difference in DNA content. Since this breakthrough, this technology has been used to produce pre-sexed offspring in over a dozen species (rabbits (Johnson et al. 1989), pigs (Johnson 1991), cattle (Cran et al. 1993), sheep (Catt et al. 1996), humans (Levinson et al. 1995), horses (Buchanan et al. 2000), buffaloes (Presicce et al. 2005), elk (Schenk \& DeGrofft 2003), dolphins (O'Brien \& Robeck 2006), dogs 
(Meyers et al. 2008), cats (Pope et al. 2008), deer (Gao et al. 2010) and goats (Bathgate et al. 2013)), and sex-sorting has become a multi-million dollar commercial enterprise throughout the international cattle industry.

This commercial success has been realised by the expenditure of considerable time, money and effort to improve not just the speed and efficiency of flow cytometric sorting, but also the viability and functional competence of the sex-sorted sperm populations. Research and development saw the two major limitations of sex-sorting by flow cytometry, 1) the speed at which sperm cells can be separated, and 2) the quality of spermatozoa following sorting and frozen storage, improved to levels acceptable for the commercial viability of the technology in dairy cattle. To achieve this a delicate balance was struck, whereby the number of spermatozoa in a dose of sexed semen was small enough to ensure profitability of production, yet retained sufficient functionally competent cells to achieve reasonable levels of fertility following artificial insemination. These developments saw Cogent UK (XY Inc.'s first licensee) release to market the first commercial straw containing 2.1 million frozen sexed bull spermatozoa for standard artificial insemination (Al) only 10 years after the aforementioned births of pre-sexed rabbits following surgical oviductal AI with fresh sex-sorted spermatozoa. Today, the technology is now available to a global cattle market through numerous XY Inc. licensees as well as 19 other laboratories operated by Sexing Technologies who are the worldwide license holder.

Since the first commercial straw of sexed semen was produced there have been various incremental improvements to sorting technology, such as the development of the orientating nozzle, and sperm processing techniques (reviewed by Sharpe \& Evans (2009), Evans (2010) and Rath et al. (2013)), but by and large relatively little has changed. Indeed several million pre-sexed calves have been produced in this time using doses of 'sexed semen' almost identical in terms of the number of spermatozoa contained within and, most importantly, fertility to that which was first reported for sexed, frozen-thawed bull spermatozoa some 15 years ago. That said, much has been learnt in this time about the fertility and function of sexed spermatozoa; the extent and source of damage induced by sorting and freezing (from collection to insemination), the effects of sperm number and insemination technique as well as species specific phenomena. Insights into the safety and efficacy of the technique have also been made. With an emphasis on ruminants (particularly cattle), the aim of this review is to discuss these biological and practical lessons associated with the use of 'sexed semen' as well as examine the most recent research and development that may see some of these traditionally held lessons overturned in the near future.

\section{Economic lessons}

Considering the commercial focus of sex-sorting research over the past 2-3 decades it is useful to briefly consider the economics of sex-sorting and the sale of sexed semen in order to frame our understanding of the subsequent biological and practical lessons that have been learnt.

The equipment, labour and maintenance involved in separating spermatozoa into $X$ and $Y$ chromosome bearing populations is profoundly expensive. Running costs aside, one must remember that the construction of a sorting facility is no small undertaking. Prior to 2004, most of the costs were all met by each individual licensee holders of the technology. However, since this point in time when Inguran LLC (dba Sexing Technologies) acquired the global rights to this technology, the economic considerations for sex-sorting cattle semen have changed. Rather than provide artificial insemination companies with standalone licenses, Sexing Technologies now operate their own sperm sexing laboratories in 19 locations worldwide under a fee for 
service model (www.sexingtechnologies.com). This change has meant the capital cost of acquiring flow cytometers and the ongoing operating costs are no longer borne by the artificial breeding companies. Instead, Sexing Technologies provides a customised service to each of these breeding organisations (J Moreno, CEO Sexing Technologies, 2014, personal communication).

Nevertheless, sperm-sexing still entails a substantial cost which must be passed on to the end user as a cost premium for purchase of a sexed straw of semen. Obviously, the aforementioned capital costs are built into the fee for service that Sexing Technologies charge each breeding company, in addition to those inherent to the time consuming process of sex-sorting. Indeed, processing inefficiencies are a key factor driving the cost premium associated with a dose of sexed spermatozoa. Current single-head flow cytometers (the most recent multi-head machines will be discussed in the latter section on recent developments), while markedly faster than earlier models, are only able to sort spermatozoa at around 6000-8000 spermatozoa of each sex (with 90\% accuracy) per second. While this appears remarkably fast considering each spermatozoon is evaluated sequentially, it is quite slow when a conventional dose of bull semen is 10-20 million total spermatozoa. The cost of labour is a substantial percentage of the price premium associated with sexed semen. Numerous studies have been conducted to quantify the economic value of sexed spermatozoa, usually in beef and dairy cattle enterprises (Taylor et al. 1988, Amann 1999, Hohenboken 1999, Seidel 2003a,b). As these investigators attest, sex-preselection will not be profitable for all livestock producers to use, or for all breeding companies to offer. Price premium influences the uptake of sex preselection technology and the reduced fertility associated with sex-sorted spermatozoa inseminated at low doses from virtually all tested species (Garner 2006), with the exception of sheep (de Graaf et al. 2007c, Beilby et al. 2009) and possibly goats (Bathgate et al. 2013), has a detrimental effect on its commercial viability. Considerable research has been conducted to understand why fertility of sex-sorted spermatozoa is reduced and develop methods for its subsequent enhancement.

\section{Biological and practical lessons}

The fertility of sex-sorted bull spermatozoa is compromised

Fertility has been recognised as an issue since the first offspring were produced using sex-sorted spermatozoa (Johnson et al. 1989). Reduced litter size (rabbits (Johnson et al. 1989), pigs (Johnson 1991)), retarded embryo development (rabbits (McNutt \& Johnson 1996), cattle (Merton et al. 1997, Lu et al. 1999)) and higher embryo mortality (rabbits (McNutt \& Johnson 1996), pigs (Bathgate et al. 2008)) have all been characteristic traits of sex-sorted spermatozoa. Sexed spermatozoa have consistently been reported to have diminished conception and pregnancy rates whether artificially inseminated fresh (sheep (Cran et al. 1997), cattle (Seidel et al. 1999a), pigs (Grossfeld et al. 2005)) or after freezing and thawing (cattle (Seidel et al. 1999b, Frijters et al. 2009)). As a general rule, sexed bull spermatozoa are expected achieve $75-80 \%$ of the fertility of conventional non-sexed, frozen-thawed semen (Schenk et al. 2009). Reduced fertility of sexed, compared to non-sexed, frozen bull semen was first documented in the late 1990s (Seidel et al. 1999b) and continues to be reported today (Dejarnette et al. 2009, Norman et al. 2010, Healy et al. 2013). In the majority of the early studies, direct comparisons between sexsorted and non-sorted spermatozoa were confounded by a difference in the number of motile spermatozoa inseminated between the two treatment groups. However, in more recent times as sorting efficiency has continued to improve, attempts have been made to elucidate whether the decrease in fertility observed following Al of sexed spermatozoa is due to reduced inseminated sperm numbers or reduced fertility of sex-sorted spermatozoa. Unfortunately, it does not appear 
reduced fertility of sex-sorted spermatozoa can be compensated for by increasing the dose of spermatozoa inseminated to the levels used in conventional Al programs. Marginal increases in fertility have been achieved (in some sires) by increasing the total number of bull spermatozoa inseminated to 3.5 or 5 million (Dejarnette et al. 2008, DeJarnette et al. 2010). Another study with several thousand inseminations comparing Al of 10 million total sexed or conventional spermatozoa failed to demonstrate comparable fertility between the two groups $(44 \%$ and $60 \%$ conception rates for Al of 10 million total sexed or non-sexed spermatozoa, respectively; Dejarnette et al. 2011). Efforts to improve the fertility of sex-sorted bull spermatozoa via the use of deep intrauterine (Kurykin et al. 2007) insemination of the uterine horn ipsilateral to ovulation and/or various methods of fixed time synchrony prior to Al (Sá Filho et al. 2012) have likewise failed to overcome the fundamental fertility problem outlined above. Indeed, it is still recommended that lactating dairy cows not be inseminated with sexed semen due to the extremely low fertility that will most likely result. However, it should be noted that this is due to the additive effect of the compromised fertility of the modern dairy cow, rather than any specific deleterious interaction between this sperm type and the lactating cow as was originally thought (Dejarnette et al. 2008, DeJarnette et al. 2009).

The use of sexed semen in MOET programs is also not recommended. This is due to the reduced fertilisation rates in superovulated heifers inseminated with sexed spermatozoa (Sartori et al. 2004), particularly when low (2 million spermatozoa) insemination doses are used (Schenk et al. 2006) or cows are used as donors (Kaimio et al. 2013). Problems with fertilisation often have a flow on effect to the number of transferable embryos produced, so it is unsurprising to discover fewer transferable embryos are produced following Al with sex-sorted spermatozoa when compared with donors inseminated with non-sexed semen (Larson et al. 2010, Soares et al. 2011). There is the occasional contrary report in the literature, but such studies usually contain relatively small animal numbers (An et al. 2010).

When considered as a whole, the clear lesson of these fertility results is that factors other than sperm number control the fertility of sexed bull spermatozoa, and that the process of flow cytometry itself must significantly alter their functional capacity (Frijters et al. 2009, Rath et al. 2013). Only the most recent advances in flow-sorted sperm processing (described at the end of this review) show evidence of amelioration of these functional problems and a subsequent reduction in the fertility gap between conventional and sexed bull semen ( $R$ W Lenz, T B Gilligan, J M deJarnette, M Utt, L Helser, K M Evans, C Gonzalez, J F Moreno \& R Vishwanath 2014, unpublished observations).

The in vitro function of bull spermatozoa is compromised

Functional studies in vitro found the sorting process results in a more advanced membrane state which resembles in vitro capacitation (evidenced by CTC analysis and protein tyrosine phosphorylation) (Bucci et al. 2012). Interestingly, these capacitation-like changes were more prominent in bull spermatozoa than boar spermatozoa (Bucci et al. 2012). Sorted spermatozoa have also demonstrated inferior motility characteristics (velocity and amplitude of lateral head displacement assessed by computer assisted sperm analysis (bull (Suh et al. 2005), sheep (de Graaf et al. 2006)), and ability to penetrate cervical mucus (de Graaf et al. 2006) compared with non-sorted spermatozoa. Sorted ram spermatozoa also bind in fewer numbers to oviduct epithelial cell monolayers (OECMs) in vitro (de Graaf et al. 2006) and detach more rapidly than non-sorted spermatozoa (Hollinshead et al. 2003). This finding suggests that binding/release within the oviduct (Gillan et al. 2000), thought to play a significant role in successful fertilisation (Hunter 1995), may be impaired by sorting, possibly due to the advanced state of the membrane. 
It is important to note that despite these aforementioned stressors, sex-sorting is also a highly discriminating technology. The orientating forces of the nozzle selects morphologically normal spermatozoa and counterstaining with a non-toxic red food dye quenches Hoechst 33342 fluorescence in non-viable cells, allowing this population to be gated to waste during sorting. The resulting population exhibits some improved sperm parameters (e.g. membrane integrity and total motility) compared to their non-sorted counterparts (ram (de Graaf et al. 2006), bull (Underwood et al. 2009b)) and some diminished traits (e.g. capacitation-like changes). The combination of these functional changes makes sorted spermatozoa a unique cell population with a reduced fertilising lifespan (except in sheep (Beilby et al. 2009)) which accounts for the aforementioned reduction in fertility.

In vitro embryo production (IVP) with sex-sorted bull spermatozoa is impaired and the resultant embryos may have altered properties

Due to the relatively small number of spermatozoa required, the use of sex-sorted spermatozoa for in vitro fertilisation (IVF) systems has long been thought a highly efficient means of utilising sex-preselection technology. While some studies report similar rates of cleavage and blastocyst formation between embryos produced from sexed and non-sexed sperm treatments (Xu et al. 2009, Carvalho et al. 2010), the majority of investigators report some reduction in blastocyst yield when sex-sorted bull spermatozoa are used (Merton et al. 1997, Lu et al. 1999, BermejoÁlvarez et al. 2008, 2010). Detailed analysis of developmental kinetics has also shown delayed onset of first cleavage in embryos fertilised by sex-sorted spermatozoa (Bermejo-Ãlvarez et al. 2010) as well as alterations to blastocyst structure (Palma et al. 2008) and developmentally important gene transcripts in some studies (Morton et al. 2007), but not others (BermejoÃlvarez et al. 2010). In sheep, gene transcripts are altered in embryos fertilised by sex-sorted spermatozoa in vivo, but not in vitro, for reasons which are yet to be determined (Beilby et al. 2011). These in vitro results tell a similar story to those conveyed in the previous section; namely, that the sorting process alters the sperm cell and this may impede its ability to fertilise the egg and produce a viable embryo. While a recent study did report similar calving rates following the transfer of in vitro embryos produced with non-sorted and sex-sorted spermatozoa, the number of animals used was relatively low (Rasmussen et al. 2013).

\section{The cause of diminished functional capacity of sex-sorted spermatozoa is multifactorial}

As for the precise cause of alterations to the sexed cell, the possibilities remain many and varied and are most likely cumulative. They may be the result of high dilution during the sorting process, known to negatively impact on the percentage of live and motile spermatozoa (Ashworth et al. 1994, Catt et al. 1997a). Reintroducing seminal plasma after sorting negates some of these deleterious effects suggesting that lower concentrations of protective seminal lipids and proteins (highly diluted during sorting) to be the cause (Catt et al. 1996, Maxwell et al. 1997, Maxwell et al. 1998, Leahy et al. 2009). As a result, supplementation of collection media with $1 \%$ seminal plasma is standard practice in modern boar sorting protocols (Grossfeld et al. 2005). However, the protective effects of seminal plasma during sorting are species-specific (Leahy \& de Graaf 2012) and exposure of bull spermatozoa to seminal plasma prior to sorting reduced the efficiency of the technique, but the potential benefits of post-sort supplementation were not tested (Burroughs et al. 2013).

Apart from dilution, the decrease in sexed sperm viability and membrane status seen post-sorting may be the result of any number of stressors to which spermatozoa are exposed 
prior to, during, or after passage through the flow cytometer. These include the addition of the fluorochrome Hoechst 33342, exposure to 351 and $364 \mathrm{~nm}$ of ultraviolet laser light, high temperatures during incubation, pressure changes, physical stress and shear forces and electrostatic gating (Seidel \& Garner 2002). Stepwise comparison of the stages of sorting found that the mechanical stress of transit through the machine (without H33342 staining or laser illumination) resulted in the largest increase in the percentage of damaged spermatozoa ((18.6\% above non-sorted, unstained controls; (Seidel \& Garner 2002)). Exposure to UV laser illumination, staining with $\mathrm{H} 33342$ or both stressors combined increased sperm damage a further $6.8,3.6$ and $0.3 \%$, respectively. Studies demonstrating the beneficial effects of decreasing sorting pressure from 50 to 40 psi on motility characteristics (Suh et al. 2005), embryo development (Campos-Chillon \& de la Torre 2003) and fertility (Suh et al. 2005) further emphasise that deterioration of sexed sperm function is largely due to mechanical/physical stress during transit through the flow cytometer. However, oxidative stress from repeated electric charging and electrostatic deflection $(3000 \mathrm{~V}$ ) is also thought to play a role (Rath et al. 2013).

Safety concerns over the use of sexed semen have been largely allayed

Concerns were also raised over potential cytotoxic and/or mutagenic damage to gametes through the use of ultraviolet activated fluorochromes. Hoechst 33342 is a reported inhibitor of DNA synthesis, and a cause of chromosomal aberrations, in hamster lung cells (Durand \& Olive 1982). An investigation suggesting H33342 and UV laser light caused an increase in chromosomal aberrations of sperm nuclei microinjected hamster eggs (Libbus et al. 1987) added weight to this argument. Further research suggests that H33342 does not impair chromatin of the mammalian spermatozoon (Garner 2009) probably due to $\mathrm{H} 33342$ binding to the minor helical groove of the DNA rather than intercalating between the base pairs (Amann 1999) like many other nucleic acid staining dyes (Schenk et al. 1999). In any case, Catt et al. (1997b) discovered no increase in endogenous DNA nicks after exposure of human spermatozoa to H33342 stain and/or ultraviolet light. Sperm Chromatin Structure Assay (SCSA) of bovine spermatozoa revealed that $\mathrm{H} 33342$, laser illumination, and both stressors combined increased DNA fragmentation cumulatively by only $2.04,1.50$ and $1.01 \%$ on top of that already caused by the mechanical insult of flow cytometry $(1.77 \%$ above that of non-sorted unstained controls (Garner et al. 2001)). More recent studies have shown frozen-thawed sexed bull spermatozoa initially display similar levels of DNA fragmentation when compared to non-sorted spermatozoa, but rapidly deteriorate to become more fragmented following $72 \mathrm{~h}$ of incubation (Gosalvez et al. 2011). Nevertheless, this damage does not appear to be extensive enough to cause any genotoxic effects in any resultant progeny to date (Parrilla et al. 2004).

Perhaps the strongest case for the safety of the technique lies in the several million animals born using sexed spermatozoa, seemingly without alteration to phenotype beyond natural levels (Amann 1999, Tubman et al. 2004). Admittedly, even if phenotypes did differ between parent and offspring, unless the mutation had an obvious effect it would most likely go unnoticed due to the difficulty inherent in detecting a random genetic change. Perhaps this uncertainty allows concern to remain over the safety of sex-sorting, particularly for human application (AshwoodSmith 1994, Johnson \& Schulman 1994, Munne 1994). Even the remotest of possibilities that the genome is being altered invoke serious ethical and philosophical dilemmas, which contribute in part to the reticence of some to utilise sexing technology.

The only evidence which may be cause for concern has come from recent studies which have tracked pregnancy outcome over several thousand or million inseminations. Four separate groups of authors have now highlighted a higher incidence of stillbirth in calves produced 
from sexed semen (DeJarnette et al. 2009, Norman et al. 2010, Healy et al. 2013, Rath et al. 2013). Interestingly, with the exception of Healy et al. (2013), the increased rate of stillbirth was isolated to male calves. One theory is that Y-chromosome spermatozoa might be included in the X-chromosome bearing sorted population due to an aneuploid condition (DeJarnette et al. 2009). Clearly this is an issue worthy of further investigation, particularly if the technology is ever to be re-launched for human application.

Whether the risks of mutation and genomic change are real or imagined it remains prudent and practical to use the minimum amount of dye (and laser power) that allows consistent resolution between $X$ and $Y$ sperm populations. The implementation of quasi continuous wave lasers c. 2004, while also improving operational efficiency, reduce the time each spermatozoon is exposed to the laser beam in addition to allowing a reduction in the amount of H33342 needed to attain X-Y resolution (Schenk et al. 2005, Sharpe \& Evans 2009). Overall laser power has also been reduced although this has not necessarily improved the developmental rate or quality of embryos derived from sexed spermatozoa (Guthrie et al. 2002).

Liquid storage of spermatozoa prior to sorting decreases sorting efficiency and post-sort sperm function

The concern has always been that relatively few sex-sorting facilities exist due to establishment and maintenance costs, but this situation has begun to change with a number of facilities established in recent years. In the last five years alone, new facilities have been established in New Zealand, Australia, Germany, France, Continental US, and Brazil. Nonetheless, in many places sorters are still often located a considerable distance from the male(s) and/or female(s) used in the sex-preselection program. After sorting, this issue has been largely overcome by many years of development to adapt cryopreservation protocols to the peculiarities of sexsorted spermatozoa. However, before sorting, an effective transport solution which does not involve animal translocation has proven more difficult to develop.

Liquid storage of spermatozoa destined for sorting within $8 \mathrm{~h}$ for gorilla (O'Brien et al. 2002), 14-17 h for dolphin (O'Brien \& Robeck 2006)), $18 \mathrm{~h}$ for stallion (Lindsey et al. 2005) or $24 \mathrm{~h}$ for ram (Hollinshead et al. 2004b) post-collection has been considered, resulting in pregnancies when inseminated into animals with (dolphin (O'Brien \& Robeck 2006)) and without (horse (Lindsey et al. 2005)) post-sort cryopreservation. In cattle, liquid storage for 24 $\mathrm{h}$ prior to sex-sorting and freeze-thawing demonstrated acceptable levels of in vitro motility and acrosome integrity in vitro (Underwood et al. 2009a) but resulted in poor pregnancy rates (7.3\% compared to $57.4 \%$ for control frozen spermatozoa; (Underwood et al. 2010a)). The poor result was achieved despite the use of double inseminations at 12 and $20 \mathrm{~h}$ post onset of standing oestrus (sperm number) and a reasonable total sperm dose (4 or 8 million total spermatozoa). These results indicate that the combination of these three technologies results in significant damage to spermatozoa, possibly through stressors in the handling process and aging of spermatozoa due to extended processing times.

If the sire is deceased, or transport cannot be relied upon to deliver semen in a timely fashion, cryopreservation is a far more attractive sperm storage option. As a result, sex-sorting from previously frozen samples has been the focus of much research over the past decade.

Initial attempts to sex-sort bull spermatozoa that has been previously frozen proved successful, but low sort rates, as well as delayed blastocyst development following IVF, were observed (Stap et al. 1998, Lu et al. 1999). Further development of the technique to improve sort speed and sperm viability (O'Brien et al. 2003) culminated in the production of lambs following the transfer of in vitro embryos produced with frozen-thawed, sex-sorted 
and re-frozen thawed ram spermatozoa (Hollinshead et al. 2004a). Frozen-thawed, sexsorted, re-frozen-thawed ram spermatozoa were also shown to have similar fertility to sexed ram spermatozoa that had been sorted from fresh semen or even non-sorted controls, when intrauterine insemination was performed (de Graaf et al. 2007b). This was seemingly the result of motility, acrosome integrity, viability and mitochondrial activity in frozen-sorted-re-frozen samples, while lower than fresh-sorted-frozen, being significantly higher than non-sorted, frozen spermatozoa (de Graaf et al. 2006). Since spermatozoa were inseminated directly into the uterus the reduced velocity and mucus penetrating ability of sexed spermatozoa observed in vitro (de Graaf et al. 2007b) were inconsequential to in vivo function under the conditions tested. Such successes stimulated similar research in cattle, but to date results in this species have been less encouraging.

In a proof of concept study, 3 pregnancies were achieved (3/74) after insemination of frozen, sexed, frozen bull spermatozoa to oestrus synchronised heifers but no live births were recorded (0/74) (Underwood et al. 2010a). In the same study, conventionally frozen semen displayed acceptable fertility (39/68 pregnant, 36/68 calved). Further in vitro tests found the sorting procedure improved the function of frozen-thawed bull spermatozoa, most likely due to the elimination of membrane-damaged sperm during the sorting process, with frozen-sorted spermatozoa retaining high motility $(66.5 \%)$ and acrosome integrity/membrane viability $(64.9$ $\%) 24 \mathrm{~h}$ after sorting (Underwood et al. 2009b). However, after re-cryopreservation (double freezing) spermatozoa had lower total motility and velocity compared to non-sorted frozenthawed spermatozoa.

In an attempt to compensate for the rapid decline in motility exhibited by frozen sexed frozen spermatozoa, this sperm type was inseminated $\left(4 \times 10^{6}\right.$ spermatozoa) close to the site of fertilisation (mid-horn of heifers; $n=20$ ) around the time of ovulation (within 6h). Again, the pregnancy rate of non-sorted frozen-thawed spermatozoa $(6 / 8 ; 75 \%)$ differed significantly from that of frozen-thawed sex-sorted re-frozen-thawed spermatozoa $(0 / 12 ; 0 \%)$ (Underwood et al. 2010b). In a further experiment, one pregnancy $(1 / 7 ; 14.3 \%)$ was recorded when a dose of $10 \times 10^{6}$ frozen-sexed-frozen spermatozoa was inseminated (Underwood et al. 2010b), which provides proof of concept, but is a long way from the commercialisation of this sperm type. For the time being, it is restricted to use in IVP systems where it appears to perform with similar ability to conventionally frozen spermatozoa (Underwood et al. 2010c).

It remains unknown why frozen-sexed-frozen spermatozoa can achieve acceptable in vivo fertility in sheep (de Graaf et al. 2007b), but not cattle. A current hypothesis is that ram spermatozoa show greater resistance to the handling-induced damages of the sorting and freezing processes, and these are the subject of previous review (de Graaf et al. 2009). This hypothesis would account for the many differences in function and fertility between sex-sorted bull spermatozoa and sex-sorted ram spermatozoa reported over the last decade. As alluded to throughout this review, sex-sorted, frozen-thawed ram spermatozoa are now recognised to have comparable if not superior fertility to that of non-sorted, frozen-thawed controls (de Graaf et al. 2009). Whether inseminated in superovulated ewes (de Graaf et al. 2007a), in non-superovulated ewes at very low doses (1 million motile (de Graaf et al. 2007c, Beilby et al. 2009)) or even when frozen both prior to and following sex-sorting (de Graaf et al. 2007b), flow-sorted ram spermatozoa result in similar or higher fertilization and/or lambing percentages compared with non-sorted spermatozoa. These results highlight a further lesson from the use of 'sexed semen': sorting affects the spermatozoa of each species in a different way and will impact on their subsequent fertility depending on the species specific context in which they are used. 


\section{Recent developments and future prospects in sperm sexing}

Fertility of sexed bull spermatozoa

Encouragingly, recent unpublished research by Sexing Technologies indicates some of the issues associated with the use of sexed spermatozoa such as dramatically reduced fertility and function may soon be ameliorated to a significant degree.

A concerted effort has been made in the last few years to understand the biochemistry of media being used for processing of sex-sorted spermatozoa, which has resulted in substantial changes in the composition of media used in several stages of the sorting process. The aim of these changes was to provide a benign environment that accommodates all these changes in $\mathrm{pH}$ and temperature that occur during the various steps of processing and sorting, but retains sperm integrity through the process. The end result is a process called SexedUltra ${ }^{\circledR}$, which is a complete overhaul of the media and conditions under which semen is processed and sorted. Using the new generation Genesis I flow cytometers and software (Cytonome/ST LLC; www. cytonomest.com), the SexedUltra ${ }^{\circledR}$ processing method was compared to the traditional XY processing methods developed in the late 1990s and early 2000s. Semen from 8 bulls was distributed to over 40 herds and inseminated into several thousand Holstein heifers. As can be seen from the results in Table 1, this trial provides recent evidence of an improvement in the fertility of sexed, frozen-thawed bull semen.

Table 1. Fertility of sex-sorted, frozen-thawed bull spermatozoa processed using traditional XY protocols or the new SexedUltra ${ }^{\circledR}$ method and inseminated into Holstein dairy heifers. Scanned pregnancy data from R W Lenz, T B Gilligan, J M deJarnette, M Utt, L Helser, K M Evans, C Gonzalez, J F Moreno \& R Vishwanath 2014, unpublished observations.

\begin{tabular}{|c|c|c|}
\hline Method of processing sexed bull spermatozoa & Number of inseminations & Scanned pregnancy rate \\
\hline$X Y$ & 3384 & $41.6 \%{ }^{\mathrm{a}}$ \\
\hline SexedUltra ${ }^{\circledR}$ & 3546 & $46.1 \%^{\mathrm{b}}$ \\
\hline
\end{tabular}

Values without common superscripts differ significantly $(\mathrm{P}<0.01)$

Substantial trials conducted in New Zealand (Livestock Improvement, New Zealand) with sex-sorted bull spermatozoa that have not undergone subsequent cryopreservation also show promising fertility results. Dairy cattle breeding in New Zealand is seasonal and in a period of 16 weeks (September to December) around 4 million dairy cattle are inseminated predominantly with fresh semen (Vishwanath \& Shannon 2000), so this system lends itself well for an intensive study on this particular type of sexed spermatozoa. The results of these trials indicate that sexed bull spermatozoa (1 million total spermatozoa/dose), when not frozen after sorting but instead inseminated within $48 \mathrm{~h}$ after initial collection, exhibit $94-96 \%$ of the fertility of non-sexed, liquid stored spermatozoa ( 1 to 2 million total spermatozoa/dose; Table 2). Remarkably, this result with unfrozen sexed spermatozoa was in lactating dairy cows rather than dairy heifers. Future studies to confirm this finding outside of the New Zealand production setting will be of great interest.

Combined, these latest fertility results are quite encouraging as the fertility of 'sexed frozen semen' has improved by about five percentage points compared with the previous method of processing and 'fresh sexed semen' is around 95\% of that of fresh conventional semen in large scale field studies in New Zealand. It will be interesting to see if these results can be applied on the world scale. The very minor decrease in fertility observed with 'fresh sexed semen' suggests that the overall process of dilution, staining and sex sorting per se is only marginally detrimental in the tested context. It could be that the bulk of the loss in fertility outlined earlier 
Table 2. Non Return Rate (NRR; 2-24 day) of sex-sorted and non-sorted, liquid stored semen inseminated into dairy cows within $48 \mathrm{~h}$ after semen collection. (Z Xu and S Ballinger 2013, unpublished observation, Livestock Improvement Corporation (LIC), New Zealand, used with permission)

\begin{tabular}{lcccc}
\hline \multirow{2}{*}{ Year } & Number of inseminations & \multicolumn{2}{c}{$2-24$ day NRR } & Sex-sorted NRR / non-sorted NRR \\
& & Sex-sorted $^{2}$ & Non-sorted $^{3}$ & \\
\hline 2011 & 8600 & $65.0 \%$ & $69.0 \%$ & $94.0 \%$ \\
2012 & 12000 & $67.0 \%$ & $69.5 \%$ & $96.4 \%$ \\
2013 & 14000 & $65.2 \%$ & $68.0 \%$ & $95.8 \%$ \\
\hline
\end{tabular}

${ }^{1}$ Non Return Rate

${ }^{2} 1$ million total sex-sorted, liquid-stored spermatozoa/AI dose

${ }^{3} 1$ to 2 million total non-sorted, liquid-stored spermatozoa/AI dose

in this review occurs mainly during the freezing and thawing process, but further testing in other settings is required for this hypothesis to be confirmed. Additionally, improvements made with the SexedUltra ${ }^{\circledR}$ process shows that there is potential to reduce the gap in fertility between sexed frozen and conventional frozen semen. No doubt further opportunities exist to enhance sperm protection during the cryopreservation process to allow for greater number of sperm to survive post thaw and improve the probability of fertilisation subsequent to Al. This is an area which deserves considerable attention in future research studies.

The last few years has also seen an increase in the number of studies which have utilised sex-sorted bull spermatozoa in timed artificial insemination programs. That is, in synchronised rather than naturally cycling cattle. As previously mentioned, timed Al has not improved the fertility of sexed semen to the levels observed when conventional semen is used (Mallory et al. 2013, Sa Filho et al. 2013, Thomas et al. 2014). However, when used appropriately, sex-sorted spermatozoa in timed Al programs displays a comparable decline in fertility to that observed in naturally cycling animals (approximately $70 \%$ of conventional semen) (Macedo et al. 2013). The key to obtaining such levels of fertility in timed Al programs appears to be insemination later than normal in order to deposit semen closer to the time of ovulation (Sales et al. 2011). Interestingly, in suckled beef cows which fail to display signs of oestrus, sex-sorted spermatozoa perform equally as well as conventional semen (36\% vs $37 \%$ pregnancy rates, respectively) if insemination of the former is delayed 20h (Thomas et al. 2014). Nonetheless, the same trial still demonstrated the compromised nature of sex-sorted spermatozoa as pregnancy rates achieved in animals that did display oestrus was $77 \%$ for conventional semen and $51 \%$ or $42 \%$ for sexed semen (inseminated at the same time as conventional or 20h later, respectively (Thomas et al. 2014)). These results suggest that with careful management sexed semen can be effectively utilised in timed artificial insemination programs in dairy and beef cattle.

\section{Advances in sperm-sorting technology}

Since the early MoFlo SX sperm sorters which had an overall sorting speed of 500 to 600 spermatozoa per second, sorting technology has continually improved as summarised in reviews by Sharpe \& Evans (2009) and Evans (2010). Since these reports, a new generation of sorters with improved speeds and efficiency have been developed by Cytonome/ST LLC (Boston, USA) exclusively for sex sorting spermatozoa. These latest Genesis machines offer significant improvements in sort efficiency through improved speed, yield and reduced labour, not to mention other developments to reduce maintenance problems and other issues that have 
a

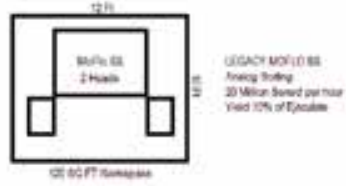

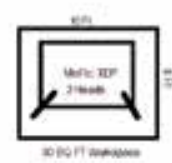

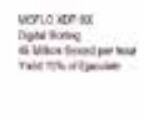

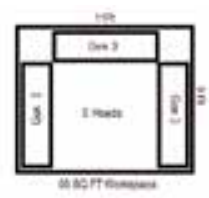

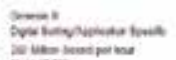
vetass b

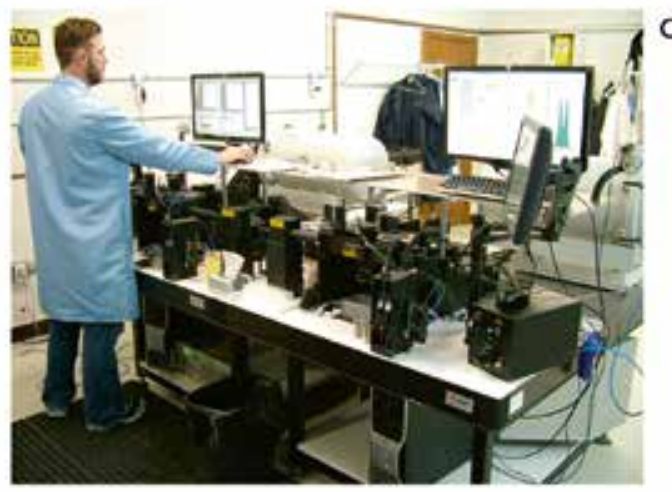

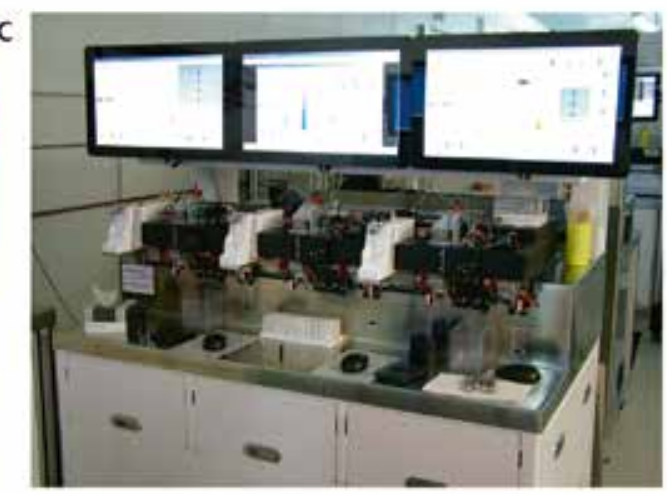

Fig. 1. a) Diagrammatic representation of the evolution of high speed sperm-sorters. Physical footprint, number of sexed cells produced per hour and relative efficiency are shown for dual head Legacy MoFlo SX (analog processing), dual head MoFlo XDP (digital processing) and nine head GENESIS III machines. b) Dual head MoFlo XDP and c) GENESIS III sperm sorters shown in operation at Sexing Technologies laboratories in Navasota Texas. The GENESIS III triple head sorter differs greatly from the MoFlo machines as it has a compact modular layout, no sheath tanks as the sheath delivery is through a new fluid delivery system that is pressurised only before entry into the sorter, new software and high level automation for alignment, drop delay, sort speed and many other features. Photos courtesy K. M. Evans (Sexing Technologies), data and schematic diagrams courtesy K. M. Evans (Sexing Technologies) and Dr John Sharpe (CEO, Cytonome/ST LLC, Boston, USA), used with permission.

traditionally afflicted flow cytometers. This evolution of sorters and their relative efficiencies is shown schematically in Fig. 1a with operational MoFlo XDP and Genesis III machines illustrated in Fig. $1 \mathrm{~b}$ and $1 \mathrm{c}$, respectively.

Clearly, the ability to sex in excess of 250 million spermatozoa per hour from a bank of sorters greatly improves the scope of sperm sexing technology to deliver adequate numbers of spermatozoa to achieve reasonable fertility for most applications. Given sufficient development in sperm processing techniques, these advances in flow sorting may see growth of sexed semen in animal industries besides cattle. There is substantial research occurring with pigs, horses and deer and it is likely that there will be more reports on fertility trials in these species in the near future. The confluence of semen biochemistry research and sorter technology improvements should ensure a step change in both fertility and efficiency of the sex sorting process.

\section{Conclusions}

Undoubtedly, the primary lesson associated with the use of sexed semen is that its fertility is to some degree compromised during the sorting process. That it is not more so, considering the dramatic ordeal which each sexed sperm cell has had to undergo, is testimony to the research efforts of the numerous investigators who have worked in this area over the past few decades and the resilience of the male gamete. Nevertheless, as a result of damage during the sorting 
process the fertility of sex-sorted, frozen-thawed bull spermatozoa remains at approximately $75 \%$ that of conventional semen when inseminated in naturally cycling heifers. Early reports suggest similar reductions in fertility when used in timed AI programs. It is not recommended for use in lactating cows or superovulated females and cannot be effectively applied to spermatozoa that have been liquid or frozen stored prior to AI, unless the sexed spermatozoa are subsequently used for IVF. The most recent research demonstrates that the fertility issue in heifers can be partially overcome ( $85 \%$ fertility of non-sexed semen) by careful development of sorting media or largely overcome in lactating cows (95\% fertility of non-sexed semen) if cells are not frozen following sorting. However, the latter solution is limited in its scope as the majority of users will still desire frozen straws. It remains to be seen if these current advances have improved fertility to the point that sexed bull semen can be used in the aforementioned non-recommended situations (e.g. MOET programs), but obviously they are a major step forward after 15 years without any reported improvement in fertility. The fact that the result with fresh sexed semen was in lactating dairy cows certainly opens another avenue for application of this technology and makes it more relevant to modern dairy production systems.

\section{Acknowledgements}

Juan Moreno, CEO, Sexing Technologies, Texas, USA; Dr John Sharpe, CEO, Cytonome/ST LLC, Boston, USA; Dr Zhenzhong Xu, Livestock Improvement Corporation, Hamilton, New Zealand.

\section{Conflicts of Interest}

R Vishwanath is a current employee of Sexing Technologies. SP de Graaf and T Leahy declare that they have no conflicts of interest.

\section{References}

Amann RP 1999 Issues affecting commercialization of sexed sperm. Theriogenology 52 1441-57.

An L, Wu ZH, Wu YF, Zhang XL, Liu X, Zhu YB, Cheng WM, Gao HM, Guo M \& Tian JH 2010 Fertility in single-ovulating and superovulated dairy heifers after insemination with low dose sex-sorted sperm. Reproduction in Domestic Animals 45 e344-e350.

Ashwood-Smith MJ 1994 Human sperm sex selection. Safety of human sperm selection by flow cytometry. Human Reproduction 9757.

Ashworth PJC, Harrison RAP, Miller NGA, Plummer JM \& Watson PH 1994 Survival of ram spermatozoa at high dilution: protective effect of simple constituents of culture media as compared with seminal plasma. Reproduction, Fertility, and Development 6 173-180.

Bathgate R, Grossfeld R, Susetio D, Ruckholdt M, Heasman K, Rath D, Evans G \& Maxwell WMC 2008 Early pregnancy loss in sows after low dose, deep uterine artificial insemination with sex-sorted, frozen-thawed sperm. Animal Reproduction Science 104 440-444.

Bathgate R, Mace N, Heasman K, Evans G, Maxwell WMC \& de Graaf SP 2013 Birth of kids after artificial insemination with sex-sorted, frozen-thawed goat spermatozoa. Reproduction in Domestic Animals 48 893-898.

Beilby KH, Grupen CG, Thomson PC, Maxwell WMC \& Evans G 2009 The effect of insemination time and sperm dose on pregnancy rate using sex-sorted ram sperm. Theriogenology 71 829-835.

Beilby KH, de Graaf SP, Evans G, Maxwell WMC, Wilkening S, Wrenzycki C \& Grupen CG 2011 Quantitative mRNA expression in ovine blastocysts produced from $\mathrm{X}$ - and Y-chromosome bearing sperm, both in vitro and in vivo. Theriogenology 76 471-481.

Bermejo-Álvarez P, Rizos D, Rath D, Lonergan P \& Gutiérrez-Adán A 2008 Can bovine in vitro-matured oocytes selectively process X- or Y-sorted sperm differentially? Biology of Reproduction 79 594-597.

Bermejo-Ãlvarez P, Lonergan P, Rath D, Gutiérrez-Adan A \& Rizos D 2010 Developmental kinetics and gene expression in male and female bovine embryos produced in vitro with sex-sorted spermatozoa. Reproduction, Fertility, and Development 22 426-436.

Bucci D, Galeati G, Tamanini C, Vallorani C, Rodriguez-Gil JE \& Spinaci M 2012 Effect of sex sorting on CTC staining, 
actin cytoskeleton and tyrosine phosphorylation in bull and boar spermatozoa. Theriogenology 77 1206-1216.

Buchanan BR, Seidel GE Jr, McCue PM, Schenk JL, Herickhoff LA \& Squires EL 2000 Insemination of mares with low numbers of either unsexed or sexed spermatozoa. Theriogenology 53 1333-1344.

Burroughs CA, Graham JK, Lenz RW \& Seidel GE Jr 2013 Seminal plasma effects on sex-sorting bovine sperm. Theriogenology 79 551-557.

Campos-Chillon LF \& de la Torre JF 2003 Effect of concentration of sexed bovine sperm sorted at 40 and 50 PSI on developmental capacity of in vitro produced embryos. Proceedings of the Annual Conference of the International Embryo Transfer Society Auckland, New Zealand Theriogenology 59506 abstract.

Carvalho JO, Sartori R, Machado GM, Mourao GB \& Dode MAN 2010 Quality assessment of bovine cryopreserved sperm after sexing by flow cytometry and their use in in vitro embryo production. Theriogenology 74 1521-1530.

Catt SL, Catt JW, Gomez MC, Maxwell WMC \& Evans G 1996 Birth of a male lamb derived from an in vitro matured oocyte fertilised by intracytoplasmic injection of a single presumptive male sperm. Veterinary Record 139 494-495.

Catt SL, O'Brien JK, Maxwell WMC \& Evans G 1997a Assessment of ram and boar spermatozoa during cellsorting by flow cytometry. Reproduction in Domestic Animals 32 251-258.

Catt SL, Sakkas D, Bizzaro D, Bianchi PG, Maxwell WMC \& Evans G 1997b Hoechst staining and exposure to UV laser during flow cytometric sorting does not affect the frequency of detected endogenous DNA nicks in abnormal and normal human spermatozoa. Molecular Human Reproduction 3 821-825.

Cran DG, Johnson LA, Miller NGA, Cochrane D \& Polge C 1993 Production of bovine calves following separation of X-chromosome and Y-chromosome bearing sperm and in vitro fertilization. Veterinary Record 132 40-41.

Cran DG, McKelvey WAC, King ME, Dolman DF, McEvoy TG, Broadbent PJ \& Robinson JJ 1997 Production of lambs by low dose intrauterine insemination with flow cytometrically sorted and unsorted semen. Proceedings Annual Conference of the International Embryo Transfer Society Nice, France Theriogenology 47267 abstract.

de Graaf SP, Evans G, Maxwell WMC \& O'Brien JK 2006 In vitro characteristics of fresh and frozen-thawed ram spermatozoa after sex-sorting and re-freezing. Reproduction, Fertility, and Development 18 867-874.

de Graaf SP, Beilby KH, O'Brien JK, Osborn D, Downing JA, Maxwell WMC \& Evans G 2007a Embryo production from superovulated sheep inseminated with sex-sorted ram spermatozoa. Theriogenology 67 550-555.

de Graaf SP, Evans G, Maxwell WMC, Cran DG \& O'Brien JK 2007b Birth of offspring of pre-determined sex after artificial insemination of frozen-thawed, sex-sorted and re-frozen-thawed ram spermatozoa. Theriogenology 67 391-398.

de Graaf SP, Evans G, Maxwell WMC, Downing JA \& O'Brien JK 2007c Successful low dose insemination of flow cytometrically sorted ram spermatozoa in sheep.
Reproduction in Domestic Animals 42 648-653.

de Graaf SP, Beilby KH, Underwood SL, Evans G \& Maxwell WMC 2009 Sperm sexing in sheep and cattle: the exception and the rule. Theriogenology 71 89-97.

DeJarnette JM, Nebel RL, Marshall CE, Moreno JF, McCleary CR \& Lenz RW 2008 Effect of sex-sorted sperm dosage on conception rates in Holstein heifers and lactating cows. Journal of Dairy Science 91 1778-1785.

DeJarnette JM, Nebel RL \& Marshall CE 2009 Evaluating the success of sex-sorted semen in US dairy herds from on farm records. Theriogenology 71 49-58.

DeJarnette JM, McCleary CR, Leach MA, Moreno JF, Nebel RL \& Marshall CE 2010 Effects of 2.1 and 3.5 $\mathrm{x}$ 10(6) sex-sorted sperm dosages on conception rates of Holstein cows and heifers. Journal of Dairy Science 93 4079-4085.

DeJarnette JM, Leach MA, Nebel RL, Marshall CE, McCleary CR \& Moreno JF 2011 Effects of sex-sorting and sperm dosage on conception rates of Holstein heifers: Is comparable fertility of sex-sorted and conventional semen plausible? Journal of Dairy Science 94 3477-3483.

Durand RE \& Olive PL 1982 Cytotoxicity, mutagenicity and DNA damage by Hoechst 33342. Journal of Histochemistry \& Cytochemistry. 30 111-116.

Evans KM 2010 Interpretation of sex sorting process and new developments. In Proceedings of the 23rd Technical Conference on Artificial Insemination and Reproduction pp 93-98. Columbia, MO: National Association of Animal Breeders.

Frijters ACJ, Mullaart E, Roelofs RMG, van Hoorne RP, Moreno JF, Moreno O \& Merton JS 2009 What affects fertility of sexed bull semen more, low sperm dosage or the sorting process? Theriogenology 71 64-67.

Gao QH, Wei HJ, Han CM, Du HZ, Zhang ZG, Zhao WG, Zhang Y \& Li S 2010 Successful low dose insemination of flow cytometrically sorted Sika (Cervus nippon) sperm in Wapiti (Cervus elaphus). Animal Reproduction Science 118 89-93.

Garner DL 2006 Flow cytometric sexing of mammalian sperm. Theriogenology 65 943-957.

Garner DL 2009 Hoechst 33342: The dye that enabled differentiation of living $\mathrm{X}$-and $\mathrm{Y}$-chromosome bearing mammalian sperm. Theriogenology 71 11-21.

Garner DL, Schenk JL \& Seidel GE Jr 2001 Chromatin stability in sex-sorted sperm. Journal of Andrology Supplement 22162.

Gillan L, Evans G \& Maxwell WM 2000 The interaction of fresh and frozen-thawed ram spermatozoa with oviducal epithelial cells in vitro. Reproduction, Fertility, and Development 12 237-244.

Gosalvez J, Ramirez MA, Lopez-Fernandez C, Crespo F, Evans KM, Kjelland ME \& Moreno JF 2011 Sex-sorted bovine spermatozoa and DNA damage: II. Dynamic features. Theriogenology 75 206-211.

Grossfeld R, Klinc P, Sieg B \& Rath D 2005 Production of piglets with sexed semen employing a non-surgical insemination technique. Theriogenology 63 2269-2277.

Guthrie HD, Johnson LA, Garrett WM, Welch GR \& Dobrinsky JR 2002 Flow cytometric sperm sorting: effects of varying laser power on embryo development in swine. 
Molecular Reproduction and Development 61 87-92.

Healy AA, House JK \& Thomson PC 2013 Artificial insemination field data on the use of sexed and conventional semen in nulliparous Holstein heifers. Journal of Dairy Science 96 1905-1914.

Hohenboken WD 1999 Applications of sexed semen in cattle production. Theriogenology 52 1421-1433.

Hollinshead FK, Gillan L, O'Brien JK, Evans G \& Maxwell WMC 2003 In vitro and in vivo assessment of functional capacity of flow cytometrically sorted ram spermatozoa after freezing and thawing. Reproduction, Fertility, and Development 15 351-359.

Hollinshead FK, Evans G, Evans KM, Catt SL, Maxwell WMC \& O'Brien JK 2004a Birth of lambs of a predetermined sex after in vitro production of embryos using frozen-thawed sex-sorted and re-frozen-thawed ram spermatozoa. Reproduction 127 557-568.

Hollinshead FK, O'Brien JK, Gillan L, Meyers M, Maxwell WMC \& Evans G 2004b Liquid storage of flow cytometrically sorted ram spermatozoa. Theriogenology 62 587-605.

Hunter RHF 1995 Ovarian control of sperm progression in the fallopian tubes. In Oxford Reviews of Reproductive Biology, pp 85-124. Ed. HM Charlton. Oxford: Oxford University Press

Johnson LA 1991 Sex preselection in swine: altered sex ratios in offspring following surgical insemination of flow sorted X-and Y-bearing sperm. Reproduction in Domestic Animals 26 309-314.

Johnson LA \& Schulman JD 1994 The safety of sperm selection by flow cytometry. Human Reproduction 9 758-759.

Johnson LA, Flook JP \& Hawk HW 1989 Sex preselection in rabbits: live births from $X$ and $Y$ sperm separated by DNA and cell sorting. Biology of Reproduction 41 199-203.

Kaimio I, Mikkola M, Lindeberg H, Heikkinen J, Hasler JF \& Taponen J 2013 Embryo production with sexsorted semen in superovulated dairy heifers and cows. Theriogenology 80 950-954.

Kurykin J, Jaakma Ü, Jalakas M, Aidnik M, Waldmann A \& Majas L 2007 Pregnancy percentage following deposition of sex-sorted sperm at different sites within the uterus in estrus-synchronized heifers. Theriogenology 67 754-759.

Larson JE, Lamb GC, Funnell BJ, Bird S, Martins A \& Rodgers JC 2010 Embryo production in superovulated Angus cows inseminated four times with sexed-sorted or conventional, frozen-thawed semen. Theriogenology 73 698-703.

Leahy T \& de Graaf SP 2012 Seminal plasma and its effect on ruminant spermatozoa during processing. Reproduction in Domestic Animals 47(Suppl 4) 207-213.

Leahy T, Marti JI, Evans G \& Maxwell WMC 2009 Seminal plasma proteins protect flow-sorted ram spermatozoa from freeze-thaw damage. Reproduction, Fertility, and Development 21 571-578.

Levinson G, Keyvanfar K, Wu JC, Fugger EF, Fields RA, Harton GL, Palmer FT, Sisson ME, Starr KM \& DennisonLagos L 1995 DNA-based X-enriched sperm separation as an adjunct to preimplantation genetic testing for the prevention of X-linked disease. Human Reproduction 10 979-982.
Libbus BL, Perreault SD, Johnson LA \& Pinkel D 1987 Incidence of chromosome aberrations in mammalian sperm stained with Hoechst 33342 and UV-laser irradiated during flow sorting. Mutation Research 182 265-274.

Lindsey AC, Varner DD, Seidel GE Jr, Bruemmer JE \& Squires EL 2005 Hysteroscopic or rectally guided, deep-uterine insemination of mares with spermatozoa stored $18 \mathrm{~h}$ at either 5 degrees $C$ or 15 degrees $C$ prior to flow-cytometric sorting. Animal Reproduction Science 85 125-130.

Lu KH, Cran DG \& Seidel GE Jr 1999 In vitro fertilization with flow-cytometrically-sorted bovine sperm. Theriogenology 52 1393-1405.

Macedo GG, Filho MFdS, Sala RV, Mendanha MF, Filho EPdC \& Baruselli PS 2013 The use of sex-sorted sperm for reproductive programs in cattle. http://dx.doi. org/10.5772/52180

Mallory DA, Lock SL, Woods DC, Poock SE \& Patterson DJ 2013 Hot topic: Comparison of sex-sorted and conventional semen within a fixed-time artificial insemination protocol designed for dairy heifers. Journal of Dairy Science 96 854-856.

Maxwell WMC, Welch GR \& Johnson LA 1997 Viability and membrane integrity of spermatozoa after dilution and flow cytometric sorting in the presence or absence of seminal plasma. Reproduction, Fertility, and Development 8 1165-1178.

Maxwell WMC, Long CR, Johnson LA, Dobrinsky JR \& Welch GR 1998 The relationship between membrane status and fertility of boar spermatozoa after flow cytometric sorting in the presence or absence of seminal plasma. Reproduction, Fertility, and Development 10 433-440.

McNutt TL \& Johnson LA 1996 Flow cytometric sorting of sperm: influence on fertilization and embryo/fetal development in the rabbit. Molecular Reproduction and Development 43 261-267.

Merton JS, Haring RM, Stap J, Hoebe RA \& Aten JA 1997 Effect of flow cytometrically sorted sperm on success rate of in vitro bovine embryo production. Proceedings Annual Conference of the International Embryo Transfer Society Nice, France Theriogenology 47295 abstract.

Meyers MA, Burns G, Arn D \& Schenk JL 2008 Birth of canine offspring following insemination of a bitch with flow-sorted spermatozoa. Proceedings of the Annual Conference of the International Embryo Transfer Society, Denver, CO, Reproduction, Fertility, and Development 20213 abstract.

Morton KM, Herrmann D, Sieg B, Struckmann C, Maxwell WMC, Rath D, Evans G, Lucas-Hahn A, Niemann H \& Wrenzycki C 2007 Altered mRNA expression patterns in bovine blastocysts after fertilisation in vitro using flowcytometrically sex-sorted sperm. Molecular Reproduction and Development 74 931-940.

Munne S 1994 Flow cytometry separation of $\mathrm{X}$ and $\mathrm{Y}$ spermatozoa could be detrimental for human embryos. Human Reproduction 9758.

Norman HD, Hutchison JL \& Miller RH 2010 Use of sexed semen and its effect on conception rate, calf sex, dystocia, and stillbirth of Holsteins in the United States. Journal of Dairy Science 93 3880-3890. 
O'Brien JK \& Robeck TR 2006 Development of sperm sexing and associated assisted reproductive technology for sex preselection of captive bottlenose dolphins (Tursiops truncatus). Reproduction, Fertility, and Development 18 319-329.

O'Brien JK, Crichton EG, Evans KM, Schenk JL, Stojanov T, Evans G, Maxwell WMC \& Loskutoff NM 2002 Sex ratio modification using sperm sorting and assisted reproductive technology - a population management strategy. Proceedings of the 2nd International Symposium on Assisted Reproductive Technology (ART) for the Conservation and Genetic Management of Wildlife, pp 224-231. Omaha, NE:Henry Doorly Zoo.

O'Brien JK, Hollinshead FK, Evans KM, Evans G \& Maxwell WMC 2003 Flow cytometric sorting of frozen-thawed spermatozoa in sheep and non-human primates. Reproduction, Fertility, and Development 15 367-375.

Palma GA, Olivier NS, Neumüller CH \& Sinowatz F 2008 Effects of sex-sorted spermatozoa on the efficiency of in vitro fertilization and ultrastructure of in vitro produced bovine blastocysts. Anatomia, Histologia, Embryologia 37 67-73.

Parrilla I, Vasquez JM, Cuello C, Gil MA, Roca J \& Di Berardino D 2004 Hoechst 33342 stain and UV exposure do not induce genotoxic effect in flow-sorted boar spermatozoa. Reproduction 128 615-621.

Pope CE, Crichton EB, Gomez MC, Dumas C \& Dresser B 2008 Birth of domestic cat kittens of predetermined sex after transfer of embryos produced by in vitro fertilization of oocytes with flow-sorted spermatozoa. Proceedings of the Annual Conference of the International Embryo Transfer Society, Denver, CO Reproduction, Fertility, and Development 20 213-214 abstract.

Presicce GA, Rath D, Klinc P, Senatore EM \& Pascale M 2005 Buffalo calves born following Al with sexed semen. Proceedings of the 9th Annual Conference of the European Society for Domestic Animal Reproduction Murcia, Spain Reproduction in Domestic Animals $\mathbf{4 0}$ 349 abstract P19.

Rasmussen S, Block J, Seidel GE Jr, Brink Z, McSweeney K, Farin PW, Bonilla L \& Hansen PJ 2013 Pregnancy rates of lactating cows after transfer of in vitro produced embryos using X-sorted sperm. Theriogenology 79 453-461.

Rath D, Barcikowski S, de Graaf S, Garrels W, Grossfeld R, Klein S, Knabe W, Knorr C, Kues W, Meyer H, Michl J, Moench-Tegeder G, Rehbock C, Taylor U \& Washausen S 2013 Sex selection of sperm in farm animals: status report and developmental prospects. Reproduction 145 R15-R30.

Sá Filho MF, Girotto R, Abe EK, Penteado L, Campos Filho EP, Moreno JF, Sala RV, Nichi M \& Baruselli PS 2012 Optimizing the use of sex-sorted sperm in timed artificial insemination programs for suckled beef cows. Journal of Animal Science 90 1816-1823.

Sa Filho MF, Mendanha MF, Sala RV, Carvalho FJ, Guimaraes LHC \& Baruselli PS 2013 Use of sex-sorted sperm in lactating dairy cows upon estrus detection or following timed artificial insemination. Animal Reproduction Science 143 19-23.

Sales JNS, Neves KAL, Souza AH, Crepaldi GA, Sala RV,
Fosado M, Campos EP, de Faria M, Sa MF \& Baruselli PS 2011 Timing of insemination and fertility in dairy and beef cattle receiving timed artificial insemination using sex-sorted sperm. Theriogenology 76 427-435.

Sartori R, Souza AH, Guenther JN, Caraviello DZ, Geiger LN, Schenk JL \& Wiltbank MC 2004 Fertilization rate and embryo quality in superovulated Holstein heifers artificially inseminated with X-sorted or unsorted sperm. Animal Reproduction 1 86-90.

Schenk JL \& DeGrofft DL 2003 Insemination of cow elk with sexed frozen semen. Proceedings of the Annual Conference of the International Embryo transfer Society Auckland, New Zealand Theriogenology 59514 abstract.

Schenk JL, Suh TK, Cran DG \& Seidel GE Jr 1999 Cryopreservation of flow-sorted bovine spermatozoa. Theriogenology 52 1375-1391.

Schenk JL, Brink Z \& Suh TK 2005 Use of competitive fertilization to evaluate a simple laser for flow cytometric sexing of bovine sperm. Proceedings of the Annual Conference of the International Embryo Transfer Society, Copenhagen, Denmark Reproduction, Fertility, and Development 306 abstract 310.

Schenk JL, Suh TK \& Seidel GE Jr 2006 Embryo production from superovulated cattle following insemination of sexed sperm. Theriogenology 65 299-307.

Schenk JL, Cran DG, Everett RW \& Seidel GE Jr 2009 Pregnancy rates in heifers and cows with cryopreserved sexed sperm: effects of sperm numbers per inseminate, sorting pressure and sperm storage before sorting. Theriogenology 71 717-728.

Seidel GE Jr 2003a Economics of selecting for sex: the most important genetic trait. Theriogenology 59 585-598.

Seidel GE Jr 2003b Sexing mammalian sperm-intertwining of commerce, technology, and biology. Animal Reproduction Science 79 145-156.

Seidel GE Jr \& Garner DL 2002 Current status of sexing mammalian spermatozoa. Reproduction 124 733-743.

Seidel GE Jr, Cran DG, Herickhoff LA, Schenk JL, Doyle SP \& Green RD 1999a Insemination of heifers with sexed frozen or sexed liquid semen. Proceedings Annual Conference of the International Embryo Transfer Society Quebec City, Quebec, Canada Theriogenology 51400 abstract 260.

Seidel GE Jr, Schenk JL, Herickhoff LA, Doyle SP, Brink Z, Green RD \& Cran DG 1999b Insemination of heifers with sexed sperm. Theriogenology 52 1407-1420.

Sharpe JC \& Evans KM 2009 Advances in flow cytometry for sperm sexing. Theriogenology 71 4-10.

Soares JG, Martins CM, Carvalho NAT, Nicacio AC, AbreuSilva AL, Campos EP, Torres JRS, Sa MF \& Baruselli PS 2011 Timing of insemination using sex-sorted sperm in embryo production with Bos indicus and Bos taurus superovulated donors. Animal Reproduction Science 127 148-153.

Stap J, Hoebe RA, Merton JS, Haring RM, Bakker PJM \& Aten JA 1998 Improving the resolution of cryopreserved $\mathrm{X}$ - and Y-sperm during DNA flow cytometric analysis with the addition of Percoll to quench the fluorescence of dead sperm. Journal of Animal Science 76 1896-1902.

Suh TK, Schenk JL \& Seidel GE Jr 2005 High pressure flow 
cytometric sorting damages sperm. Theriogenology 64 1035-1048.

Taylor JF, Phillips KR \& Thomaszewski MA 1988 Net present value and economic merit of sexed semen and splitting units of semen for Australian Holsteins. Journal of Dairy Science 71 3100-3111.

Thomas JM, Lock SL, Poock SE, Ellersieck MR, Smith MF \& Patterson DJ 2014 Delayed insemination of non-estrous cows improves pregnancy rates when using sex-sorted semen in timed artificial insemination of suckled beef cows. Journal of Animal Science 92 1747-1752.

Tubman LM, Brink Z, Suh TK \& Seidel GE Jr 2004 Characteristics of calves produced with sperm sexed by flow cytometry/cell sorting. Journal of Animal Science 82 1029-1036.

Underwood SL, Bathgate R, Maxwell WMC \& Evans G 2009a Development of procedures for sex-sorting frozenthawed bovine spermatozoa. Reproduction in Domestic Animals 44 460-466.

Underwood SL, Bathgate R, Maxwell WMC \& Evans G $2009 \mathrm{~b}$ In vitro characteristics of frozen-thawed, sex-sorted bull sperm after refreezing or incubation at 15 or $37^{\circ} \mathrm{C}$. Theriogenology 72 1001-1008.

Underwood SL, Bathgate R, Ebsworth M, Maxwell WMC \& Evans G 2010a Pregnancy loss in heifers after artificial insemination with frozen-thawed, sex-sorted, re-frozenthawed dairy bull sperm. Animal Reproduction Science 118 7-12.

Underwood SL, Bathgate R, Maxwell WMC \& Evans G $2010 \mathrm{~b}$ Birth of offspring after artificial insemination of heifers with frozen-thawed, sex-sorted, re-frozen-thawed bull sperm. Animal Reproduction Science 118 171-175.

Underwood SL, Bathgate R, Pereira DC, Castro A, Thomson PC, Maxwell WMC \& Evans G 2010c Embryo production after in vitro fertilization with frozen-thawed, sex-sorted, re-frozen-thawed bull sperm. Theriogenology 73 97-102.

Vishwanath R \& Shannon P 2000 Storage of bovine semen in liquid and frozen state. Animal Reproduction Science 62 23-53.

Xu J, Chaubal SA \& Du F 2009 Optimizing IVF with sexed sperm in cattle. Theriogenology 71 39-47. 